\title{
Changes in the Hydro-mechanical and Thermo-physical Characteristics of Liquid Food Products (for Example, Milk) under the Influence of Natural Surfactants
}

\author{
Yuriy Bilonoga ${ }^{1,4 *},{\text { Volodymyr } \text { Stybel }^{3}, \text { Enrico Lorenzini }}^{2}$, Oksana Maksysko $^{1}$, Uliana Drachuk ${ }^{1}$ \\ ${ }^{1}$ Faculty of Food Technologies and Biotechnology, Stepan Gzytsky Natoinal University of Veterinary Medicine and \\ Biotechnologies Lviv, 50 Pekarska, Lviv 79010, Ukraine \\ ${ }^{2}$ Department of Industrial Engineering, Alma Mater Studiorum-University of Bologna, viale Risorgimento 2, Bologna 40136, \\ Italy \\ ${ }^{3}$ Faculty of Veterinary Medicine, Stepan Gzytsky Natoinal University of Veterinary Medicine and Biotechnologies Lviv, 50 \\ Pekarska, Lviv 79010, Ukraine \\ ${ }^{4}$ Lviv Institute of Economy and Tourism Lviv, Menzinsky 8, Lviv 79007, Ukraine
}

Corresponding Author Email: yuriy_bilonoha@ukr.net

https://doi.org/10.18280/ti-ijes.630103

Received: 20 January 2019

Accepted: 22 March 2019

\section{Keywords:}

vegetable oils, average thickness of the laminar boundary layers, surface number, surfactants, coefficient of surface tension

\begin{abstract}
The surface properties of vegetable oils are investigated. It is shown that the investigated vegetable oils at the interface between the liquid-gas, liquid-solid surfaces, liquid-liquid behave as surface-active substances for milk. It is shown that the hydromechanical characteristics of milk are changing, which moves in the pipeline or apparatus, namely in the boundary layer under the influence of plant surface-active substances (surfactants). It is shown that the reduction of the surface tension coefficient minimizes the thickness of the boundary layer A in the system wall of the pipeline-milk, which means that it increases the average flow velocity in it and as a consequence, such a system is capable of effectively transmitting the amount of heat. A numerical range of the surface criterion for milk was found for adding surfactants.
\end{abstract}

\section{INTRODUCTION}

Empirical criterion equations, which are often encountered in scientific and reference literature, carry a powerful experimental material and describe multicomponent and multifactorial systems.

It is known that the hydromechanical characteristics of the liquid-phase refrigerant flow are crucial for the passage of heat exchange processes in the pipeline wall-flow system. For the effective operation of the heat-exchange apparatus, it is necessary that the movement of liquid heat-transfer media is carried out in a turbulent mode. However, a laminar boundary layer (LBL) appears in the near-wall region of the pipeline. The specific thermal resistance of LBLs is an order of magnitude greater than the specific thermal resistance of the turbulent flow zone, but the overall thermal resistance is small, since the average thickness of the LBL is very small [1].

We proposed to consider the process of motion of liquids in pipelines or apparatus, taking into account surface tension forces at the interface between solid and liquid phases [1]. In this work, we derived a surface number (formula 1), which in LBL acquires large values in comparison with the Froude and Reynolds numbers [1].

$P_{0}=\frac{1}{N} \frac{2 \pi \sigma \cos \theta}{\mu v_{z}} ;$

where $N=\frac{v_{z} \delta \rho}{\mu}=10.47-11.5[2]$
This number is somewhat similar to a capillary number $C$ [3].

$C=\frac{\mu v_{z}}{\sigma}$

The capillary number includes the rate of lifting the liquid in the capillary, depending on the change in the coefficient of surface tension and the coefficient of the dynamic viscosity of the liquid.

But in our proposed surface number includes the average velocity of liquids in LBL $v_{z}$, as well as the modified Reynolds number $N$ and the wetting surface hydrophilicity $\cos \theta$.

From equality (1) it can be seen that the numerical values of the surface number essentially depend on the coefficient of surface tension. However, it is known that the coefficient of surface tension of liquids, that is, liquid-phase coolants can be reduced by introducing optimal concentrations of surfactants (SAS) into them.

\section{PROBLEM FORMULATION}

We in [4] proposed the possibility of increasing the overall heat transfer coefficient of a shell-and-tube heat exchanger during heat treatment of milk by adding vegetable oil to it with a concentration of 0.5 mass. $\%$, Which is a SAS to the milk components. Instead of the base component - water, it is proposed to use a $47 \%$ propylene glycol aqueous solution. Based on the fact that the food industry produces a large 
range of vegetable oils, which are successfully used for the manufacture, for example, of functional dairy products, in this work we set ourselves the following tasks:

- to study the main physico-chemical characteristics of a number of vegetable oils;

- determine the degree of hydrophobicity of a number of vegetable oils;

- to study the surface properties of vegetable oils using the methods of correlation analysis;

- find out which vegetable oil and in which optimal concentration it will most effectively influence as a surfactant on the surface properties of milk, namely, to minimize its surface tension coefficient;

- show the change in hydro-mechanical and thermophysical characteristics of milk in LBL under the action of vegetable oils;

- show how vegetable oils in optimal concentrations affect the average thickness of the LBL and how this affects the average flow rate of the coolant in the near-surface area of the LBL.

\section{RESULTS}

\subsection{Justification of the choice of vegetable oils as SAS to the components of milk}

In recent years, there has been a significant increase in interest in the study of vegetable oils of various origins. When creating combined fatty products, oils from unconventional raw materials are widely used - pumpkin, watermelon, amaranth, grape seeds, wheat germ [5]. Uses oils, for example, as natural surfactants, in particular for the intensification of certain heat-mass-exchange processes [6].

3.1.1 The study of the physico-chemical properties of a number of vegetable oils

We have carried out comprehensive studies of the physicochemical parameters of a number of vegetable oils, namely, density $\rho$, dynamic viscosity coefficient $\mu$, and surface tension coefficient $\sigma$.

The density, the coefficient of dynamic viscosity, the coefficient of surface tension of the oils was determined according to generally accepted methods [7].

The dynamic viscosity coefficient was measured using a RHEOTEST 2.1 rotational viscometer. Measurements were made using coaxial cylinders at a deformation rate $D_{r}=3$ $1312 \mathrm{~s}^{-1}$. According to the results of the measure, reological curves in coordinates were constructed «offset voltage $\tau_{r}$ deformation rate $D_{r}$ and «dynamic viscosity $\mu$ - strain rate $D_{r}{ }^{»}$. In Figure $1-2$ shows the reological curves of the investigated vegetable oils.

An analysis of the results suggests that, with the exception of the initial part $D_{r}=-50 \mathrm{~s}^{-1}$, the vegetable oils under study behave as low-structured fluids with a quasi-Newtonian flow pattern. In the investigated range of strain rates, the dependence $\tau_{r}-D_{r}$ is described by Newton's linear law $\tau_{r}=$ $\eta D_{r}$, and the value of effective dynamic viscosity remains almost constant. The practical absence of a hysteresis loop when measured in the "rise-fall" mode of the strain rate indicates a low degree of structurization and a high rate of relaxation processes during deformation (flow) of vegetable oils. For the majority of vegetable oils studied, the value of the dynamic viscosity coefficient lies in the interval $70-77$
mPa.s. From this series, there is corn oil $(\mu=33 \mathrm{mPa} . \mathrm{s})$ and olive oil $(\mu=81 \mathrm{mPa} . \mathrm{s})$.
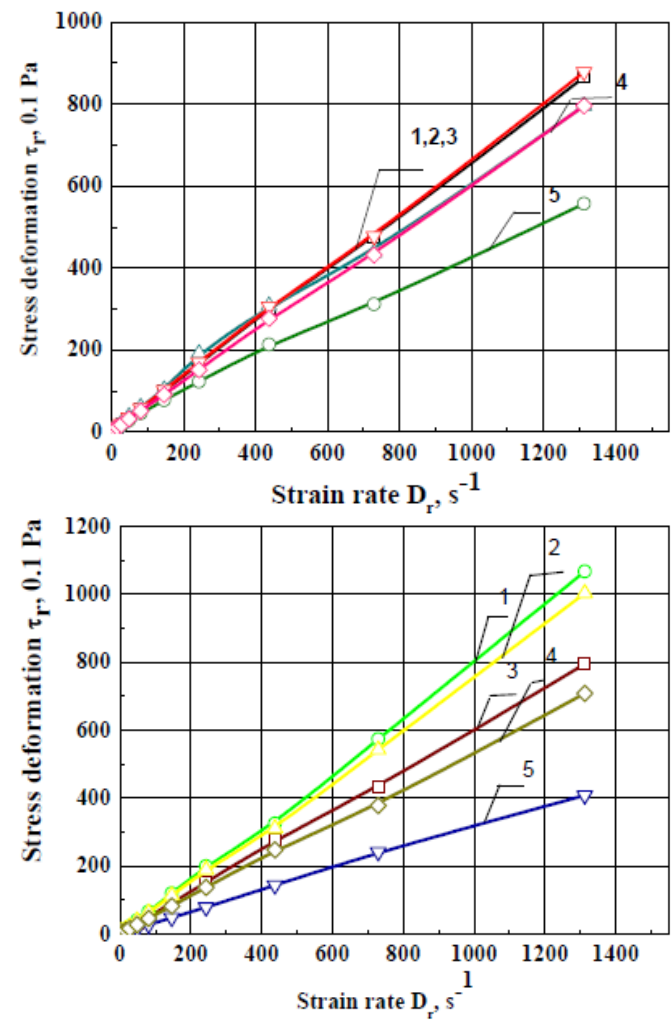

Figure 1. Dependence of the strain stress $\tau_{r}$ on the strain rate $D_{r}$ : (a) 1 - pumpkin; 2 -wheat germ; 3 - grape seed; 4 soybean; 5 - sunflower; (b) 1 - olive; 2 - peanut; 3 rapeseed; 4 - walnut; 5 - corn
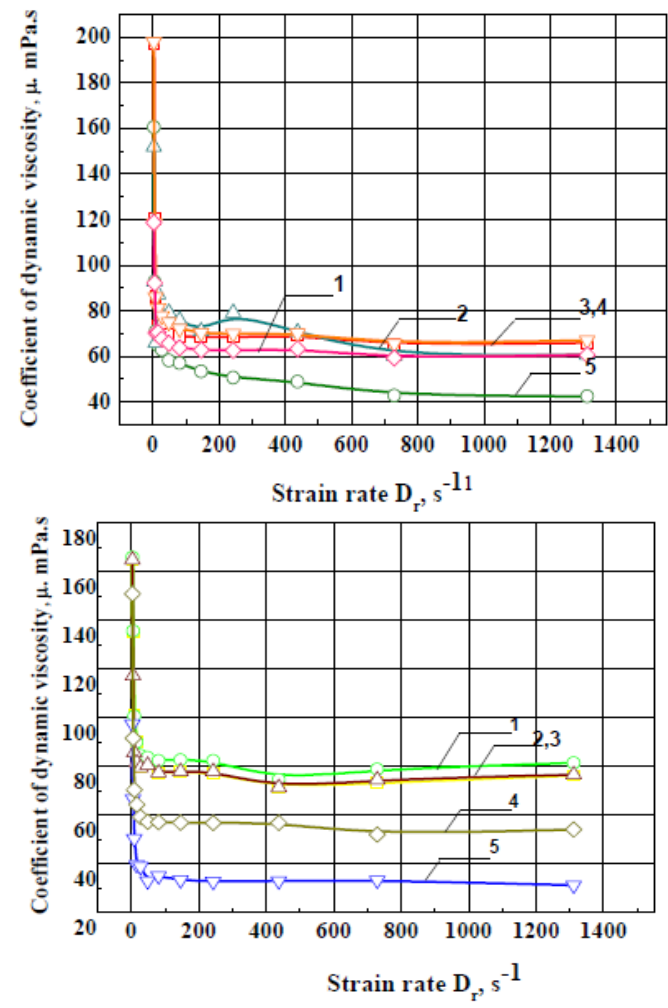

Figure 2. Dependence of the dynamic viscosity coefficient $\mu$ on the strain rate $D_{r}$ : (a) 1 - soybean; 2 - pumpkin; 3 - grape seed; 4-wheat germ; 5 - sunflower; (b) 1 - olive; 2 rapeseed; 3 - peanut; 4 - walnut;5 - corn 
The surface tension coefficient was measured by the method of maximum pressure of an air bubble according to the classical scheme [6]. The value of density, dynamic viscosity coefficient and surface tension coefficient of the vegetable oils studied are given in Table 1.

Table 1. Physical characteristics of vegetable oils

\begin{tabular}{|c|c|c|c|}
\hline Vegetable Oil & $\begin{array}{c}\text { Density } \\
\rho, \\
\text { kg. }\end{array}$ & $\begin{array}{c}\text { Dynamic } \\
\text { Coefficient } \\
\text { of Viscosity } \\
\mu, \text { mPa.s }\end{array}$ & $\begin{array}{l}\text { Coefficient of } \\
\text { Surface } \\
\text { Tension } \sigma \\
\text { mH.m } \\
\end{array}$ \\
\hline Pumpkin Oil & 918.6 & 70.0 & 38.6 \\
\hline Sunflower Oil & 920.7 & 50.5 & 39.5 \\
\hline Wheat Germs Oil & 923.0 & 76.6 & 40.0 \\
\hline Grape Brush Oil & 954.3 & 72.5 & 40.0 \\
\hline Soybean Oil & 919.6 & 64.4 & 40.5 \\
\hline Rapeseed Oil & 917.4 & 77.0 & 44.1 \\
\hline Olive Oil & 912.3 & 81.0 & 45.5 \\
\hline Peanut Oil & 917.0 & 77.4 & 62.5 \\
\hline Corn Oil & 919.4 & 33.0 & 69.4 \\
\hline Walnut Oil & 919.6 & 57.2 & 72.7 \\
\hline
\end{tabular}

\subsubsection{Determination of the hydrophobicity of vegetable oils}

The ability of vegetable oils to wet the solid surface was evaluated by analyzing the shape of a drop of liquid on the surface of a solid [7]. To assess the wetting ability of vegetable oils, polytetrafluoroethylene (Teflon) was used as a solid, since it refers to materials whose surface is considered to be hydrophobic (non-polar). Therefore, the ability of the oil to wet the non-polar (hydrophobic) surface of Teflon can serve as a measure of the relationship of oil molecules in the hydrophobic phase - in this case - the degree of hydrophobicity of vegetable oil. To determine which wetting angle setting is used, which allows you to project drops on the screen. Measuring the main dimensions of the drop (height $\mathrm{h}$, diameter $\mathrm{d}$ ), we calculated the wetting angle.

To assess the relationship of vegetable oils to the polar environment, a method was used based on the ability of a water-insoluble liquid to spread over the surface of the water.

To determine the shape and size of a drop, the previously obtained results of measurements of its projections on microphotographs were respectively mathematically processed. It should be noted that the size and shape of the drop are determined by the location of the points that lie on the projection of its surface.

The calculated values $\cos \theta$ and $\theta$ for these oils, as well as the spreading area of $A_{s p r}$ oil on the surface of the water are given in Table 2.

Table 2. Values $\cos \theta, \theta$, and the reduced area of spreading $A_{s p r}$ vegetable oils

\begin{tabular}{|c|c|c|c|}
\hline Vegetable Oil & $\cos \theta$ & $\theta$ & $\begin{array}{c}\mathbf{1 0}^{\mathbf{2}} \boldsymbol{A}_{\text {spr }} \\
\mathbf{m}^{2} / \mathbf{g}^{*}\end{array}$ \\
\hline Grape Brush Oil & 0.6333 & 50.7 & 3.96 \\
\hline Wheat Germs Oil & 0.6354 & 50.6 & 5.53 \\
\hline Peanut Oil & 0.5300 & 58.0 & 3.01 \\
\hline Walnut Oil & 0.5012 & 59.9 & 1.74 \\
\hline Pumpkin Oil & 0.6845 & 46.8 & 15.4 \\
\hline Rapeseed Oil & 0.5647 & 55.6 & 3.71 \\
\hline Corn Oil & 0.5055 & 59.6 & 2.35 \\
\hline Sunflower Oil & 0.6624 & 48.5 & 7.88 \\
\hline Olive Oil & 0.5636 & 55.7 & 3.55 \\
\hline Soybean Oil & 0.5949 & 53.5 & 3.76 \\
\hline
\end{tabular}

From the data in Table 2, we can conclude that the studied oils are characterized by a fairly high affinity for the nonpolar (hydrophobic) surface of Teflon - wetting angle for all oils $\theta<90^{\circ}$, that is, from the point of view of surface activity, they are substances with the predominant influence of the hydrophobic component.

Analyzing the results of the study of the surface properties of vegetable oils (surface tension coefficient, wetting angle, spreading over the water surface), it is obvious that vegetable oils at the liquid-gas interface, liquid-solid surface, liquidliquid behaves as surface-active substances. At the same time, the nature of the manifestation of these properties can be divided into two groups of vegetable oils.

The first group is rapeseed, sunflower, soybean oil, grape seed oil and wheat germ oil, olive and pumpkin oil. These oils are characterized in comparison with other, relatively low value of the surface tension coefficient $-39-45 \mathrm{mN} \cdot \mathrm{m}^{-1}$, which indicates a rather high surface activity of these oils.

The second group - peanut oil, walnut oil, corn oil, characterized by a large value of the surface tension coefficient $-62-72 \mathrm{mN} \cdot \mathrm{m}^{-1}$.

The oils of the first group are characterized by a high content of unsaturated fatty acids - xolein, linoleic and linolenic. Interestingly, for all oils of group 2, a high 12-14\% content of palmitic acid is characteristic. A similar trend is observed for data on the wettability of a solid surface. So, the wetting angle for oils of group 1 is $51-56^{\circ}$, while for oils of 2 groups $-58-60^{0}$. Oils of group 2 are characterized by a low ability to spread on the surface of water, which generally correlates well with the results of measuring the wetting angle. The surface film for these oils is (1.7-3.0) $10^{-2} \mathrm{~m}^{2} / \mathrm{g}$, while for the remaining oils, except pumpkin and sunflower oil, (3.5-5.5) $10^{-2} \mathrm{~m}^{2} / \mathrm{g}$. An anomalously high ability to spread on the surface of the water shows pumpkin oil, for which $A_{s p r}=15.410^{-2} \mathrm{~m}^{2} / \mathrm{g}$. The results of measurements of the surface properties of the vegetable oils studied indicate a higher degree of "hydrophobicity" of peanut, corn oil and walnut oil. They are characterized by a low affinity for water (low ability to spread over the surface of the water), as well as a high value of the surface tension coefficient.

3.1.3 The study of the surface properties of vegetable oils using the methods of correlation analysis

To establish the relationship between the surface properties of vegetable oils (surface tension coefficient, wetting angle and spreading area) and assessing such a relationship between these parameters, correlation analysis was used, in which the connection tightness is determined by the pair correlation coefficient $r$.

Were found the pair correlation coefficients $r_{\sigma-\cos \theta}$ between the surface tension coefficient $\sigma$ and the wetting angle $\theta$, between the wetting angle $\theta$ and the spread area $A_{s p r}-r_{\theta-A s p r}$ and between the surface tension coefficient $\sigma$ and the spreading area $A_{s p r} .-r_{\sigma-A s p r}$ is the germination of vegetable oils.

Thus, the pair-correlation coefficients $\theta-\sigma$ and $\theta-A_{s p r}$ are quite close to unity and equal, respectively, $r_{\theta-\sigma}=0.8686$ and $r_{\theta-S}=0.8134$. The correlation of experimental data $r_{A s p r-}$ $\sigma=0.7004$ is less reliable, however, in this case, the effect of viscosity on the dynamics of the spreading of oil over the surface of water may be manifested. At the same time, the analysis of correlation dependences (Figure 3) allows us to distinguish two groups of vegetable oils, for each of which a 
close correlation is observed between the respective pairs of parameters.

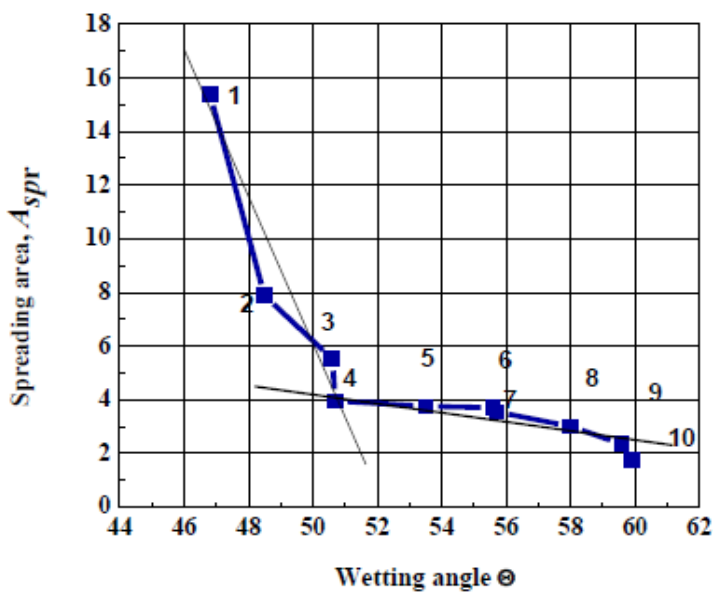

Figure 3. The correlation ratio $A_{s p r}-\theta$ investigated vegetable oils: 1 -pumpkin seed oil; 2 - sunflower oil; 3 - wheat germ oil; 4 - grape seed oil; 5 - soybean oil; 6 - rapeseed oil, 7 -

olive oil, 8 - peanut oil; 9 - corn oil; 10 -walnut oil

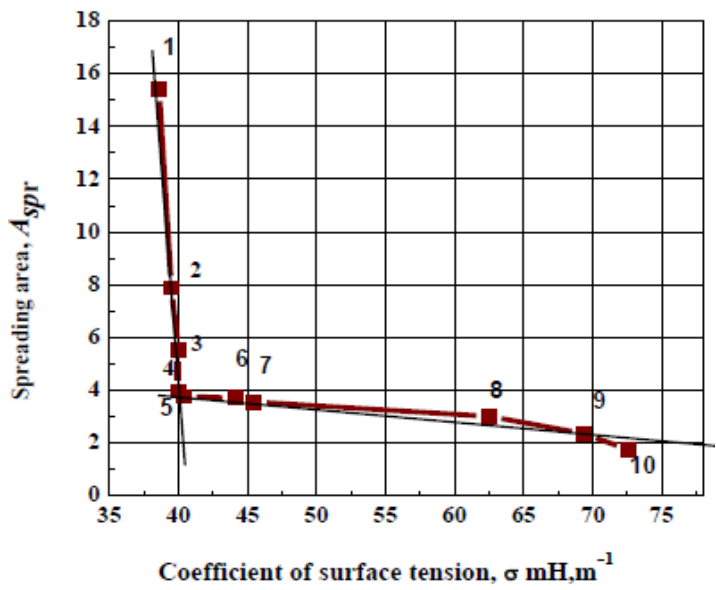

Figure 4. The correlation ratio $A_{s p r}-\sigma$ investigated vegetable oils: 1 - pumpkin seed oil; 2 - sunflower oil; 3 - wheat germ oil; 4 - grape seed oil; 5 - soybean oil; 6 - rapeseed oil, 7 olive oil, 8 - peanut oil; 9 - corn oil; 10 - walnut oil

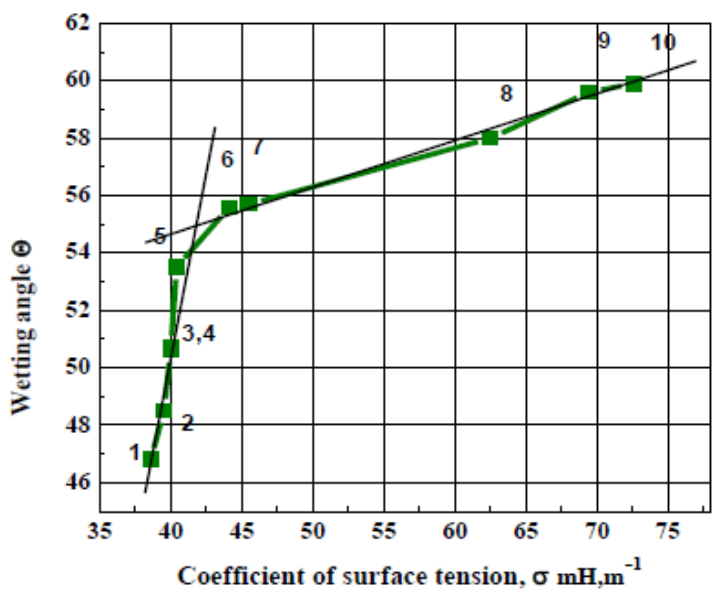

Figure 5. Correlation relations $\theta-\sigma$, investigated vegetable oils: 1 - pumpkin oil; 2 - sunflower oil; 3 - wheat germ oil; 4 - grape seed oil; 5 - soybean oil; 6 - rapeseed oil, 7 - olive oil, 8 - peanut butter; 9 - corn oil; 10 - walnut oil
The first group includes pumpkin, sunflower oil, wheat germ oil and grape seed oil, soybean oil. For this group of oils, a strongly pronounced relationship of the parameters $A_{s p r}-\theta, A_{s p r}-\sigma$ and $\theta-\sigma$. This is a group of oils that are characterized by high surface activity compared to other oils.

The second group of oils is rapeseed, olive, peanut, corn and walnut oil, for which there is also an almost linear correlation between the respective pairs of parameters, although the relationship between these parameters is much weaker. Establishing the reasons for this behavior of vegetable oils requires complex approaches and is not part of the goal of our research.

\subsection{The effect of the concentration of vegetable oils on the coefficients of the surface tension of milk}

We have carried out a series of experiments to ensure changes in the surface tension coefficient, the cosine of the wetting angle, and the viscosity of an emulsion of natural origin (milk) when vegetable oils of the first group are introduced into it. this is a group of oils that are characterized by high surface activity. the milk was placed in a vessel with a thermostat, where it was stirred with a stirrer with a rotational speed of $3 \mathrm{~s}^{-1}$. additives were added to the milk, and one sample was left as a control.

According to the measurement results, graphs of the dependence of the surface tension coefficients and the dynamic viscosity coefficient on the concentration of vegetable oils were constructed (Figure 6).

Analyzing these graphs, we see that at certain concentrations of natural surfactants there is a maximum decrease in the coefficient of surface tension of milk, these concentrations will be considered optimal, since they correspond to the critical concentration of micelle (CCM) formation.

\subsection{Change of hydromechanical and thermo-physical characteristics of milk in the LBL under the action of vegetable oils}

Set the numerical range of the surface number for milk and show its change for adding the optimal concentrations of vegetable oils, which can be used as natural SAS to the components of milk.

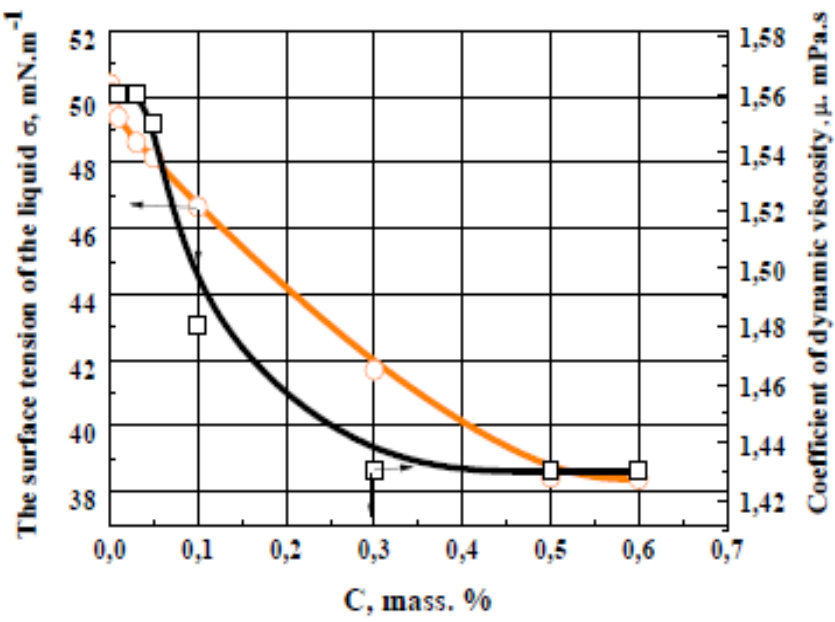

(a) 


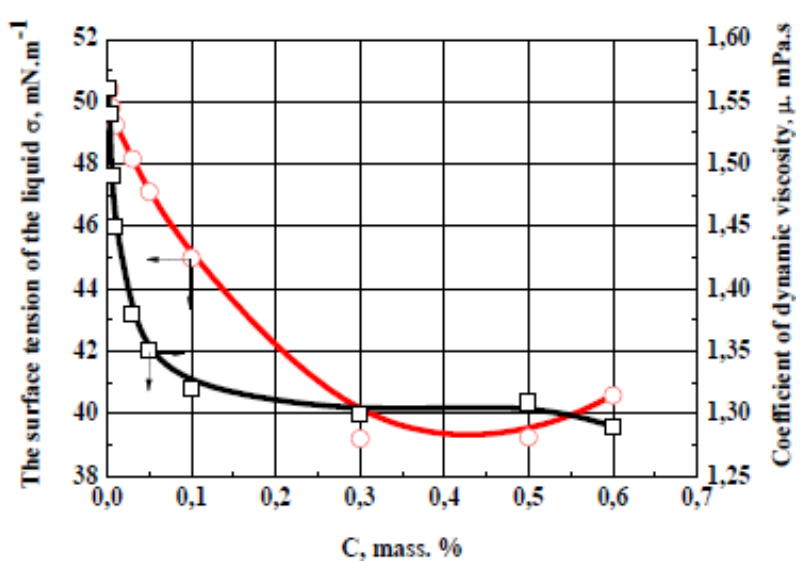

(b)

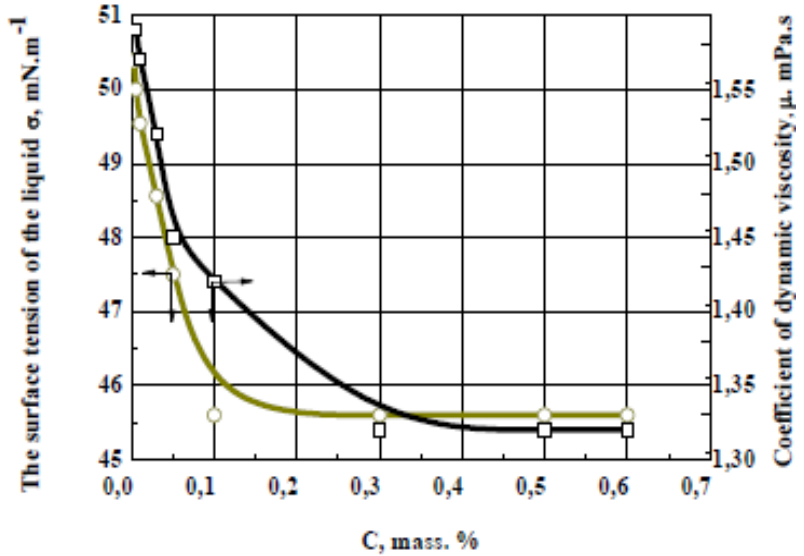

(c)

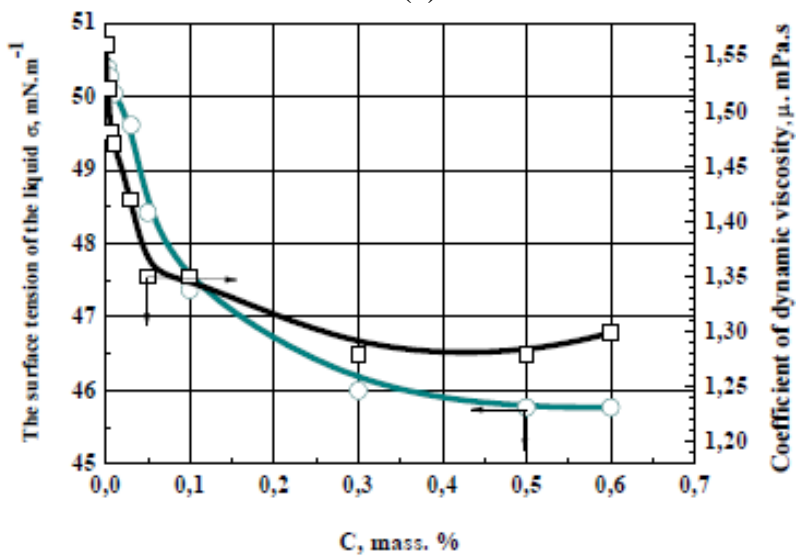

(d)

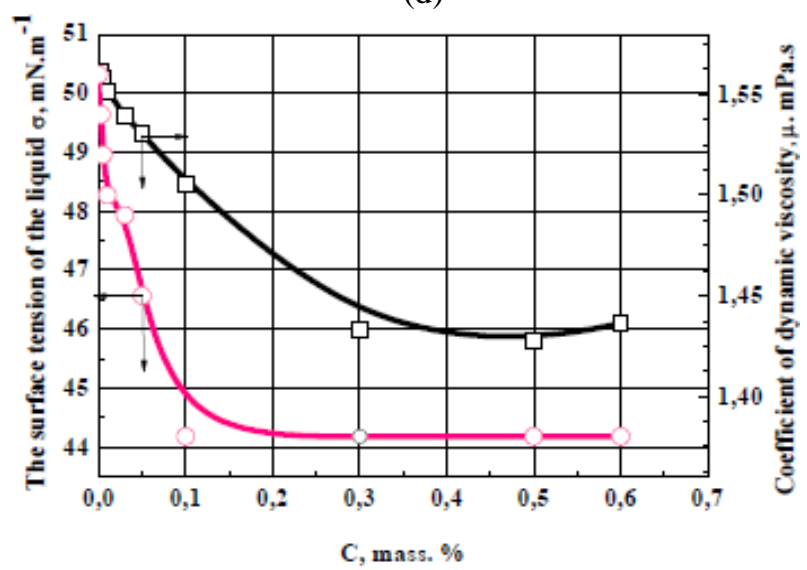

(e)

Figure 6. The dependence of the surface tension coefficient $\sigma$ and the dynamic viscosity coefficient $\mu$ of milk on the concentration of oil: (a) pumpkin oil, (b) sunflower oil (c) wheat germ oil, (d) grape seed oil (e) soybean oil
At the enterprises of the food, pharmaceutical and processing industries, the average speed of movement of liquids in pipelines is $v \approx 1 \mathrm{~m} \cdot \mathrm{s}^{-1}$, the diameter of the pipeline is $d=21.10^{-3} \mathrm{~m}$, the length of the pipeline is $L=3 \mathrm{~m}$. [2]. Speed in the wall layers was found from the modified Reynolds criterion $v_{z}=\frac{N \mu}{\delta \rho}$, assuming a value of $N=10.5$ [2]. The average thickness of the LBL was calculated by the formula (3) [1]:

$\delta=\frac{\frac{d^{2}}{\operatorname{Re} \mu} \sqrt{\frac{2 \sigma \cos \theta \rho}{f L}}}{K_{T}} ;$

The number of the surface number for milk and milk for the optimal concentration of the primary implants was determined by the formula (4).

$P_{0}=\frac{1}{N} \frac{2 \pi \sigma \cos \theta}{\mu v_{z}}$

The Table 3 shows the image of the middle LBL producer and the flow of milk from the optimal concentration of fresh milk to the milk.

Table 3. The change in the average thickness of LBL and its speed from the optimal concentration of natural SAS

\begin{tabular}{|c|c|c|}
\hline Heat carrier & $\begin{array}{c}\text { Average } \\
\text { thickness LBL, } \\
\text { m } \\
\end{array}$ & $\begin{array}{c}\text { Velocities } \\
\text { in the wall } \\
\text { layers } \mathrm{m}_{\mathrm{s}} \mathrm{s}^{-1} \\
\end{array}$ \\
\hline Milk & $113 \cdot 10^{-6}$ & 0.141 \\
\hline $\begin{array}{c}\text { Milk + }(0,5 \div 0,515) \text { mass. } \% \\
\text { pumpkin oil }\end{array}$ & $82 \cdot 10^{-6}$ & 0.155 \\
\hline $\begin{array}{c}\text { Milk }+(0,5 \div 0,515) \text { mass. } \% \\
\text { sunflower oil }\end{array}$ & $86 \cdot 10^{-6}$ & 0.153 \\
\hline $\begin{array}{c}\text { Milk }+(0,3 \div 0,315) \text { mass. } \% \\
\text { wheat germs oil }\end{array}$ & $92 \cdot 10^{-6}$ & 0.152 \\
\hline $\begin{array}{c}\text { Milk }+(0,1 \div 0,15) \text { mass. } \% \\
\text { Grape brush oil }\end{array}$ & $92 \cdot 10^{-6}$ & 0.150 \\
\hline $\begin{array}{c}\text { Milk }+(0,5 \div 0,515) \text { mass. } \% \\
\text { Soybean oil } \\
\end{array}$ & $98 \cdot 10^{-6}$ & 0.149 \\
\hline $\begin{array}{c}\text { Milk }+(0,3 \div 0,315) \text { mass. } \% \\
\text { Rapeseed oil }\end{array}$ & $102 \cdot 10^{-6}$ & 0.145 \\
\hline $\begin{array}{c}\text { Milk }+(0,5 \div 0,515) \text { mass. } \% \\
\text { Olive oil }\end{array}$ & $103 \cdot 10^{-6}$ & 0.144 \\
\hline $\begin{array}{c}\text { Milk }+(0,5 \div 0,515) \text { mass. } \% \\
\text { Peanut oil } \\
\end{array}$ & $106 \cdot 10^{-6}$ & 0.143 \\
\hline $\begin{array}{c}\text { Milk }+(0,5 \div 0,515) \text { mass. } \% \\
\text { Corn oil } \\
\end{array}$ & $108 \cdot 10^{-6}$ & 0.142 \\
\hline $\begin{array}{c}\text { Milk }+(0,3 \div 0,315) \text { mass. } \% \\
\text { Walnut oil }\end{array}$ & $109 \cdot 10^{-6}$ & 0.142 \\
\hline
\end{tabular}

Analyzing the data in the table shows that the average thickness of LBL significantly depends on the coefficient of surface tension of the liquid and decreases under the action of vegetable oils. Thus, the average thickness of LBL with the introduction of optimal concentrations of oils in the first group of milk decreased by 1.37-1.15 times, and for the oils of the second group - 1.12-1.04 times. By reducing the average thickness of the LBL, the speed in it increases, and this intensifies the passage of the amount of heat through it. At the same time, the binding energy between the wall of the pipeline and LBL milk is reduced, the "sticking" of the liquid to the walls is minimized. 
Consider the flow cross-section in the pipeline for the turbulent (T) mode of fluid flow (Figure 7). Velocity vectors in it are distributed like a parabola, but with a wider apex. However, in T mode, there is an LBL of medium thickness at the walls. Due to the mutual friction and "sticking" of the liquid to the walls, the velocity of the flow at the wall itself tends to zero and increases with distance from the wall.

The surface number is a function of the surface tension coefficient of the coolant. As the surface tension coefficient decreases, the numerical values of the surface number $P_{0}$ also decrease. Compare the value of the surface number for water and for milk under identical conditions. For water, the value of the surface number is 254 , while for milk it is 128 . This can be explained by the fact that the surface tension

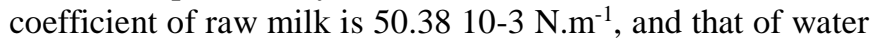
- $73.2510-3 \mathrm{~N} . \mathrm{m}^{-1}$, that is, for milk is much less. The low value of the coefficient of surface tension of milk is due to the content of milk fat and proteins, that is, the content of phospholipids, which are also surfactants.

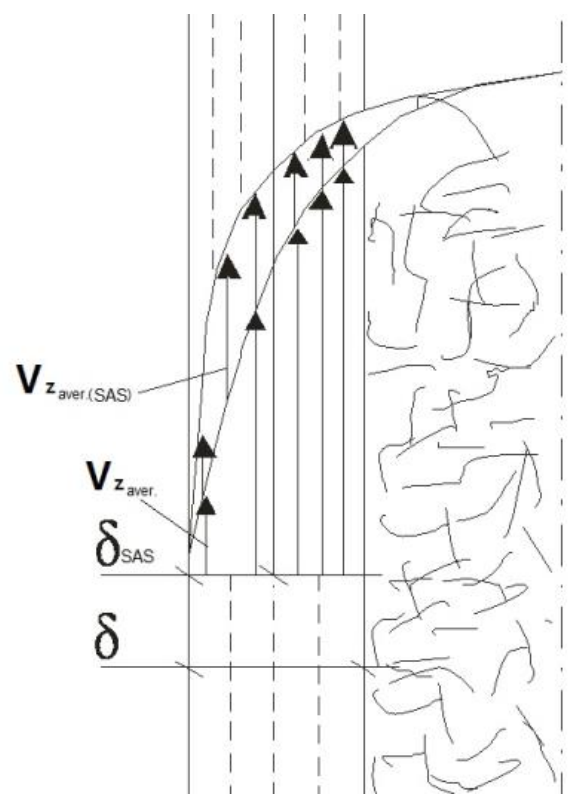

Figure 7. The distribution of velocity vectors in LBL [1]

The graph of the dependence of the surface number of milk on the coefficient of its surface tension at optimal concentrations of vegetable oils is shown in Fig. 8.

For oils of the first group, the value of the surface number is in the range of 127-106, and for oils of the second group, this range is much narrower $127-120$. This is due to the fact that the oils of the first group are more surface-active and capable of lowering the coefficient of the surface tension of milk 1.37-1.15 times. For oils of the second group, the coefficient of the surface tension of milk decreases insignificantly 1.14-1.06 times. Since all values of the surface number lie on the straight line and are superimposed (Figure 8), then with such a dependence, by measuring the surface tension coefficient after the introduction of surfactant into the coolant, it is possible to determine the surface number and average velocity in LBL.

For oils of the first group, the value of the surface number is in the range of 127-106, and for oils of the second group, this range is much narrower 127-120. This is due to the fact that the oils of the first group are more surface-active and capable of lowering the coefficient of the surface tension of milk 1.37-1.15 times.

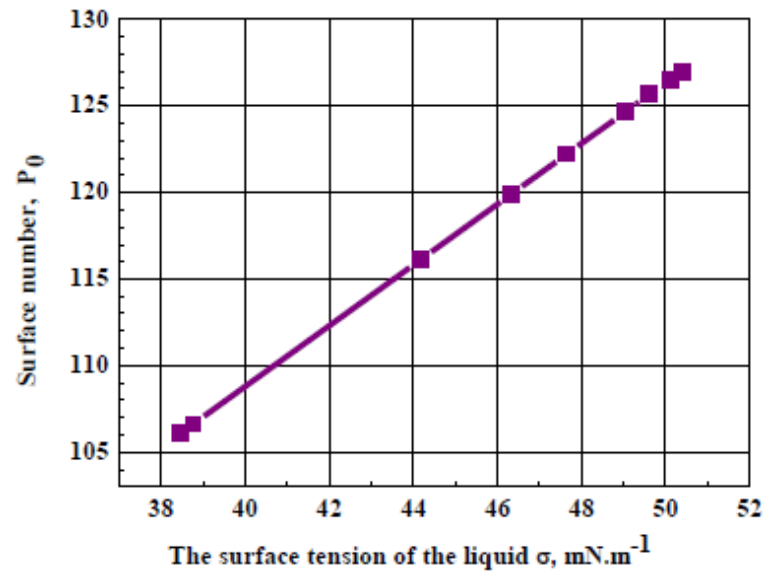

Figure 8. The dependence of the surface number of the coefficient of the surface tension of milk when adding to it the optimal concentrations of vegetable oils

For oils of the second group, the coefficient of the surface tension of milk decreases insignificantly 1.14-1.06 times. Since all values of the surface number lie on the straight line and are superimposed (Fig. 8), then with such a dependence, by measuring the surface tension coefficient after the introduction of surfactant into the coolant, it is possible to determine the surface number and average velocity in LBL.

$P_{o}=\frac{1}{N} \frac{2 \pi \sigma \cos \theta}{\mu v_{z}}=\frac{\mu}{v_{z} \delta \rho} \frac{2 \pi \sigma \cos \theta}{\mu v_{z}}=\frac{2 \pi \sigma \cos \theta}{\delta \rho v_{z}^{2}}$;

where $v_{z}=\frac{2 \pi \sigma \cos \theta}{\mu N P o}$;

Consequently, at low concentrations of SAS to milk, the surface tension coefficient and the average thickness of the LBL decreases significantly and the average speed in this layer is maximum, the surface number is minimal, which allows us to intensify the amount of heat passing in such conditions.

\section{CONCLUSIONS}

1. Based on experimental studies of the surface properties of vegetable oils (surface tension coefficient, wetting angle, spreading over the surface of water), it was found that at the interface of liquid-gas, liquid-solid surface, liquid-liquid vegetable oils behave like surfactants to components of milk.

2. Based on the experimental data and the results of statistical analysis, the coefficients of the pair correlation of the surface properties of the oils under study were obtained. $\theta-\sigma\left(r_{\theta-\sigma}=0.868\right)$ and $A_{s p r}-\theta\left(r_{\theta-S}=0.813\right)$ and $A_{s p r}-\sigma\left(r_{A s p r}\right.$ $-\sigma=0.7004)$.

3. Based on the correlation analysis of the surface properties (surface tension coefficient, wetting angle, spreading over the water surface) of vegetable oils and the nature of their manifestation, two groups of vegetable oils were established. The first group includes pumpkin, sunflower oil, wheat germ oil and grape seed oil, soybean oil. The second group is rapeseed, olive, peanut, corn and walnut oil.

4. Experimentally found the optimal concentration of vegetable oils to milk, at which the coefficient of surface 
tension is minimal. It is shown that the minimum value of the surface number is observed at optimal SAS concentrations, that is, with the minimum value of the surface tension coefficient.

5 . The range of surface numbers for aqueous solutions of SAS (86-140) and milk at the optimum concentration of natural SAS (127-106) has been established. It is shown that the surface number is a function of the values of the surface tension coefficient of the coolant.

6. Reducing the surface tension coefficient minimizes the average thickness of the LBL, as a result, increases the average velocities in the LBL, which contributes to more efficient heat transfer.

\section{REFERENCES}

[1] Bilonoga Y, Maksysko O. (2017). Modeling the interaction of coolant flows at the liquid-solid boundary with allowance for the laminar boundary layer. International Journal of Heat and Technology 35(3): 678-682. http://dx.doi.org/ 10.18280/ijht.350329

[2] Cook G. (1973). A processes and devices dairy industry. Moskva, Food Industry, pp. 84-95.

[3] Bonn D, Eggers J, Indekeu J, Meunier J, Rolley E. (2009). Wetting and spreading. Reviews of Modern Physics 81(2): 739-805. https://doi.org/10.1103/RevModPhys.81.739

[4] Bilonoga Y, Maksysko O. (2018). Specific features of heat exchangers calculation considering the laminar boundary layer, the transitional and turbulent thermal conductivity of heat carriers. International Journal of Heat and Technology 36(1): 11-20. https://doi.org/10.18280/ijht.360102

[5] Yu LP, Hammond EG. (2000). The modification and analysis of vegetable oil for cheese making. Journal of the American Oil Chemists' Society 77(9): 911-916. https://doi.org/10.1007/s11746-000-0144-z

[6] Kralova I, Sjöblom J. (2009). Surfactants used in food industry: A review. Journal of Dispersion Science and Technology 30(9): 1363-1383. https://doi.org/10.1080/01932690902735561
[7] Adamson AW, Gast AP. (1997). Physical chemistry of surfaces. Interscience Publishers, New. Eng., 13 p. 755.

[8] Marchand A. (2011). Why is surface tension a force parallel to the interface? American Journal Physical 79(10): 999-1008. https://doi.org/10.1119/1.3619866

\section{NOMENCLATURE}

$\begin{array}{ll}A & \text { spreading area, } \mathrm{m}^{2} \\ \cos \theta & \text { cosine of wetting angle } \\ d & \text { diameter of the pipe, } \mathrm{m} \\ D_{r} & \text { strain rate } \\ f & \text { hydraulic friction coefficient } \\ K_{T} & \text { turbulization coefficient } \\ L & \text { length of the pipe, } \mathrm{m} \\ N & \text { modified Reynolds number in LBL } \\ P_{o} & \text { supface number in LBL } \\ \operatorname{Re}_{\mathrm{R}} & \text { Reynolds number } \\ \operatorname{Re}_{c r} & \text { critical Reynolds number } \\ V_{z} & \text { average fluid velocity in LBL, } \mathrm{m} \cdot \mathrm{s}^{-1}\end{array}$

\section{Greek symbols}

$\delta \quad$ average thickness of the LBL, $\mathrm{m}$

$\mu \quad$ dynamic viscosity coefficient, Pa.s

$\rho \quad$ fluid density, $\mathrm{kg} . \mathrm{m}^{-3}$

$\sigma \quad$ surface tension of the liquid, N.m ${ }^{-1}$

$\tau_{r} \quad$ stress deformation

\section{Subscripts}

aver average

cr critical

\section{Abbreviations}

$C C M \quad$ critical concentration of micelle

$L B L \quad$ laminar boundary layer

SAS surfactants 